\title{
Determination of Rifampicin by Peroxomonosulfate-Cobalt(II) Chemiluminescence System
}

\author{
MA, Yong ${ }^{a, b}$ (马永) ZHANG, Bo-Tao ${ }^{a}$ (张波涛) ZHAO, Li-Xia ${ }^{*}$ (赵利霞) \\ GUO, Guang-Sheng ${ }^{b}$ (郭广生)ＬIN, Jin-Ming ${ }^{\star, a, c}$ (林金明) \\ ${ }^{a}$ State Key Laboratory of Environmental Chemistry and Ecotoxicology, Research Center for Eco-environmental \\ Sciences, Chinese Academy of Sciences, Beijing 100085, China \\ ${ }^{b}$ State Key Laboratory of Chemical Resource Engineering, Beijing University of Chemical Technology, \\ Beijing 100029, China \\ ${ }^{c}$ Department of Chemistry, Tsinghua University, Beijing 100084, China
}

\begin{abstract}
Rifampicin can enhance the chemiluminescence (CL) of peroxomonosulfate-cobalt(II) system, and the CL intensity is strongly dependent on the rifampicin concentrations. Based on this phenomenon, a rapid and sensitive flow injection CL method was developed for the determination of rifampicin. The relative CL intensity was linear with the rifampicin concentration over the range of $5 \times 10^{-8}$ to $1 \times 10^{-6} \mathrm{~g} \bullet \mathrm{mL}^{-1}(r=0.9991)$, the detection limit was $7 \times 10^{-9} \mathrm{~g} \bullet \mathrm{mL}^{-1}(S / N=3)$, and the relative standard deviation was $2.7 \%$ for $6 \times 10^{-7} \mathrm{~g} \bullet \mathrm{mL}^{-1}$ rifampicin $(n=11)$. Furthermore, this method was successfully applied to the determination of rifampicin in real eye drop and capsules sample.
\end{abstract}

Keywords chemiluminescence, peroxomonosulfate, rifampicin, cobalt(II), flow injection analysis

\section{Introduction}

Rifampicin (3-\{[(4-methyl-1-piperazinyl)imino]methyl \}rifamycin), is a semi-synthetic antibiotic drug, the structure of which was shown as follows.

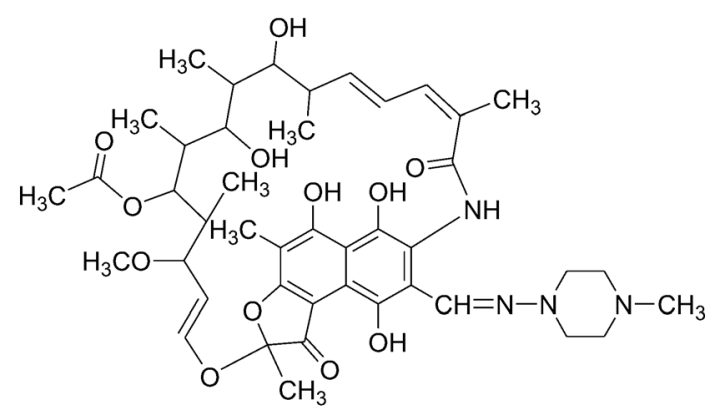

Rifampicin is widely used alone or in combination with other drugs such as isoniazid and pyrazinamide in the treatment of tuberculosis and other infectious diseases. ${ }^{1-4}$ In recent years, rifampicin has been also used in some serious infection, such as human immunodeficiency virus (HIV), cancer and so on. ${ }^{5}$ The daily dose of rifampicin is $10 \mathrm{mg} / \mathrm{kg}$ body weight, and the absolute bioavailability of rifampicin is reported to be $50 \%-$ $68 \%$ of this dose. Rifampicin is metabolized in the liver mainly by deacetylation and is excreted with its metabolites in bile. Hence, care must be taken when rifampicin is used in patients with liver disease. On basis of these, determination of rifampicin concentrations in the pharmaceutical products and biological fluids might be of value in examining the curative effect and optimizing the dose. At present, the usual methods for the determination of rifampicin include micellar electrokinetic capillary chromatography (MEKC), ${ }^{6}$ adsorptive stripping voltammetry, ${ }^{7,8}$ spectrophotometry ${ }^{9-11}$ and HPLC, ${ }^{12-14}$ but all the methods have the high detection limits which are not usable for microanalysis and tracking the concentration of rifampicin in vivo.

Chemiluminescence (CL), which owns excellent sensitivity, wide linear dynamic range and requires relatively simple and inexpensive instrumentation, is a powerful analytical technique. ${ }^{15-17}$ Nowadays, the CL has been applied to the determination of rifampicin. $\mathrm{Li}$ et al. ${ }^{18}$ made use of continuous-flow chemiluminescence with artificial neural network calibration to carry out the simultaneous determination of the rifampicin and isoniazid, but both the relative standard errors and the detection limit were not satisfactory. Yang et al. ${ }^{19}$ changed the HPLC with the CL detection, and detected the rifampicin and isoniazid with a hexacyanoferrate(III) CL system, in fact, the change was difficult and the detection limit was also not satisfactory. Liang et al. ${ }^{20}$ reported that they detected the rifampicin with an electrochemiluminescence method, which was sensitive, and the results in the determination of rifampicin in real samples were relatively satisfactory. The peroxomono-

\footnotetext{
* E-mail: zlx@ @rcees.ac.cn; jmlin@mail.tsinghua.edu.cn; Tel. \& Fax: 0086-010-62841953 Received July 30, 2007; revised December 3, 2007; accepted January 7, 2008.

Project supported by the National Natural Science Foundation of China (Nos. 20437020, 50273046) and Graduate Innovation Foundation of Chinese Academy of Sciences (No. YXLW-3).
} 
sulfate-cobalt(II) CL system has been developed as a potential CL analysis method in determination of drugs and environmental contamination, such as riboflavin in Vitamin $\mathrm{B}_{2}$ tablets and injections and 2-naphthol, benzothiazole and humic substance in natural water. ${ }^{21,22}$ To our knowledge, it has not been reported whether the peroxomonosulfate-cobalt(II) CL system can be used for determination of rifampicin, and in order to search a better determination method, determination of rifampicin by peroxomonosulfate-cobalt(II) CL system was investigated.

In this work, we found a strong CL phenomenon when a trace amount of rifampicin was added to peroxomonosulfate-cobalt(II) mixed solution and the CL intensity was strongly dependent on rifampicin concentration. Based on the strong enhancing effect of rifampicin on this CL system, a new, rapid, simple, sensitive and inexpensive method was proposed to determinate rifampicin. Compared with the other CL methods, ${ }^{18-20}$ it has much better linearity and lower detection limit. Furthermore, the method has been used for the determination of rifampicin in real eye drop and capsule samples with satisfactory results.

\section{Experimental}

\section{Reagents}

All the reagents used in these experiments were of analytical grade or higher without further purification. Water was purified using a compact ultra pure water system $\left(18.3 \mathrm{M} \Omega \cdot \mathrm{cm}^{-1}\right.$, Barnstead, Iowa, USA). A $10^{-4}$ $\mathrm{g} \bullet \mathrm{mL}^{-1}$ rifampicin stock solution was prepared by dissolving $10 \mathrm{mg}$ of rifampicin (Sigma-Aldrich, St. Louis, USA) in $1 \mathrm{~mL}$ of anhydrous methanol and diluting to $100 \mathrm{~mL}$ with water, then stored at $4{ }^{\circ} \mathrm{C}$ and protected from the light. Solutions of $\mathrm{KHSO}_{5}$ available in the form of a triple salt $\left(2 \mathrm{KHSO}_{5} \cdot \mathrm{KHSO}_{4} \cdot \mathrm{K}_{2} \mathrm{SO}_{4}\right)$ as oxone (Alfa Aesar-A Johnson Matthey Company, Ward Hill, USA) and cobalt(II) sulfate $\left(\mathrm{CoSO}_{4}\right)$ (Beijing Chemical Reagent Company, Beijing, China) were prepared daily.

\section{Apparatus}

Batch chemiluminescence experiments were carried out with a BPCL luminescence analyzer (Institute of Biophysics, Chinese Academy of Sciences, Beijing, China). A luminometer (Lumiflow LF-800, Microtec NITI-ON, Funabashi, Japan) was used for flow-injection chemiluminescence experiments. The flow injection analysis (FIA) system is illustrated in Figure 1. PTFE tubing (1.0 $\mathrm{mm}$ i.d.) was used as connection material in the flow system. Reagent solutions were delivered by two peristaltic pumps (SJ-1211, Atto, Tokyo, Japan) through three flow lines.

Rifampicin standard solution or sample solution was injected into the carrier stream (water) with a $150 \mu \mathrm{L}$ loop injector. A $18 \mathrm{~cm}$ mixing tubing was used to enhance the mixing of $\mathrm{HSO}_{5}^{-}$and $\mathrm{Co}^{2+}$ solutions due to that the CL signal exhibited a maximum at $c a .3 \mathrm{~min}$

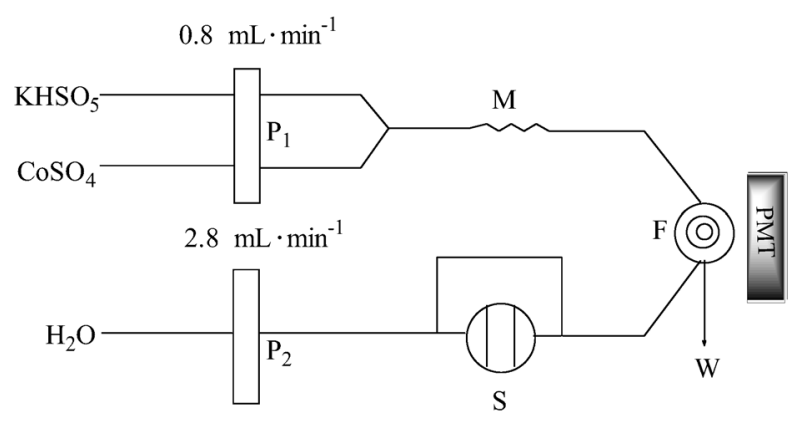

Figure 1 Schematic diagram of the flow injection system for peroxomonosulfate-cobalt(II) chemiluminescence. P1 and P2, peristaltic pumps; S, $150 \mu \mathrm{L}$ sample injector; $\mathrm{M}$, mixing tubing (1.0 mm i.d., $18 \mathrm{~cm}$ long); F, flow cell; and W, waste.

after mixing. The flow cell was a flat spiral-coiled colorless glass tube $(1.0 \mathrm{~mm}$ i.d.; total diameter of the flow cell, $3 \mathrm{~cm}$ ) and placed in front of the window of the photomultiplier tube (PMT, operated at $-800 \mathrm{~V}$ ). The concentration of rifampicin was quantified via the peak height of the relative CL intensity obtained by subtracting the blank $\mathrm{CL}$ intensity emitted when mixing $\mathrm{HSO}_{5}^{-}$ and $\mathrm{Co}^{2+}$ solutions.

\section{Sample preparation}

The eye drop and capsule samples were purchased from Wuhu Sanyi Pharmaceutical Factory and Chengdu Jinhua Pharmaceutical Co. Ltd., respectively. The eye drops were dissolved in the buffer offered by the pharmaceutical factory, and $1 \mathrm{~mL}$ of the solution was diluted to $100 \mathrm{~mL}$ as stock solution. Several capsules were accurately ground into fine powder and mixed. $150 \mathrm{mg}$ of powders were weighed accurately and dissolved with 50 $\mathrm{mL}$ of water and filtered. $1 \mathrm{~mL}$ of the filtrate was diluted to $100 \mathrm{~mL}$ as stock solution. Both the stock solutions were appropriately diluted when determinated, respectively.

\section{Results and discussion}

\section{Batch CL measurements}

The catalytic decomposition of peroxymonosulfate by $\mathrm{Co}^{2+}$ has been known as a potential CL analysis method for a long time. ${ }^{23,24}$ The dynamic profile of chemiluminescence of rifampicin in $\mathrm{HSO}_{5}^{-} / \mathrm{Co}^{2+}$ system in batch experiments is shown in Figure 2. From the CL kinetic curve, mixing of $\mathrm{HSO}_{5}^{-}$solution with $\mathrm{Co}^{2+}$ solution gave evidence of CL emission, which would be the blank CL emission in CL flow system. A stronger and sharper CL signal appeared when the rifampicin solution was added to the $\mathrm{HSO}_{5}^{-} / \mathrm{Co}^{2+}$ mixed solution. The CL reached the maximum intensity at $2 \mathrm{~s}$ and decayed within $10 \mathrm{~s}$. This result meant that the reaction of rifampicin with the reactive species was a fast process. Therefore, the present CL system could be developed as a flow-injection-CL analysis for the rapid determination of rifampicin. 


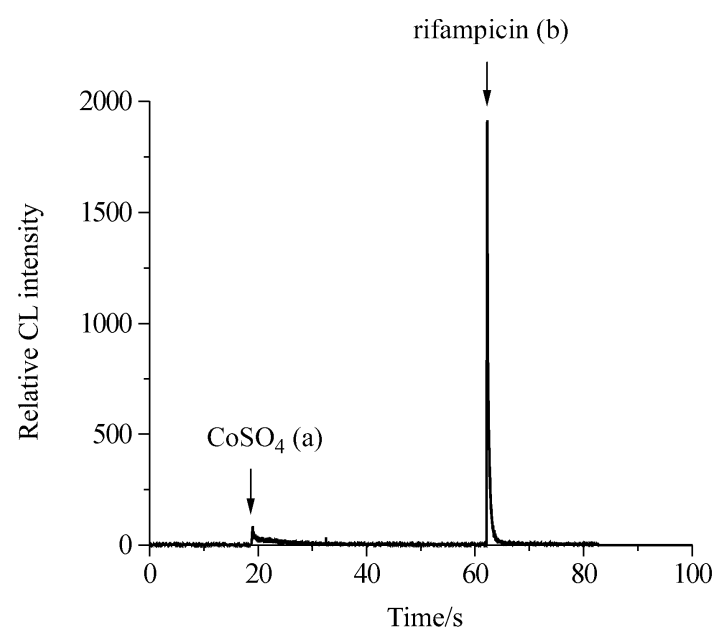

Figure 2 Chemiluminescence kinetic curve of $\mathrm{HSO}_{5}^{-}-\mathrm{CoSO}_{4}$ rifampicin system: (a) injection of $\mathrm{CoSO}_{4}$ solution into $\mathrm{KHSO}_{5}$ solution and (b) injection of rifampicin solution into $\mathrm{KHSO}_{5} /$ $\mathrm{CoSO}_{4}$ mixed solution. The concentrations of $\mathrm{KHSO}_{5}, \mathrm{CoSO}_{4}$ and rifampicin were $0.02 \mathrm{~mol} \cdot \mathrm{L}^{-1}, 0.01 \mathrm{~mol} \cdot \mathrm{L}^{-1}$ and $6.0 \times 10^{-7} \mathrm{~g} \bullet$ $\mathrm{mL}^{-1}$, respectively. The volume of each reagent solution was 50 $\mu \mathrm{L}$.

\section{Optimization of the flow-injection-CL of $\mathrm{HSO}_{5}^{-} / \mathrm{Co}^{2+}$ system}

In order to determine the optimum operating condition for the flow system, the CL intensity for $6 \times 10^{-7}$ $\mathrm{g} \cdot \mathrm{mL}^{-1}$ rifampicin was measured with respect to the reaction variables.

The flow rate is an important factor in flow-injection-CL analysis which influences not only analytical efficiency but also the sensitivity of the system. The effect of the flow rate on CL intensity was examined in the range of $1.0-5.2 \mathrm{~mL} \cdot \mathrm{min}^{-1}$, according to Figure 3 . The results showed that the CL signal increased with increasing the flow rate of carrier stream in the range $1.0-2.8 \mathrm{~mL} \cdot \mathrm{min}^{-1}$, probably because this CL reaction was a rapid reaction; however, above the flow rate 2.8 $\mathrm{mL} \cdot \mathrm{min}^{-1}$, the CL intensity declined, probably because higher flow rates with shorter contact time resulted in insufficient CL reaction. So, a flow rate of $2.8 \mathrm{~mL}$ $\mathrm{min}^{-1}$ for the carrier stream was selected as optimum. On the other hand, according to Figure 4. The CL intensity was also correlated with the flow rates of $\mathrm{KHSO}_{5}$ and $\mathrm{CoSO}_{4}$ in the range $0.2-3.2 \mathrm{~mL} \cdot \mathrm{min}^{-1}$. Based on the investigation result, the flow rate of 0.8 $\mathrm{mL} \cdot \mathrm{min}^{-1}$ was selected as an appropriate condition.

The concentrations of $\mathrm{KHSO}_{5}$ and $\mathrm{CoSO}_{4}$ had a very important effect on the relative CL intensity for the determination of rifampicin. The effect of $\mathrm{KHSO}_{5}$ concentration on the CL signal was investigated in the range of $0.005-0.06 \mathrm{~mol} \cdot \mathrm{L}^{-1}$. The relative $\mathrm{CL}$ intensity reached its peak at the concentration of $0.02 \mathrm{~mol} \cdot \mathrm{L}^{-1}$ as shown in Figure 5, so it was operated as one of the FIA optimum condition. The effect of $\mathrm{CoSO}_{4}$ concentration on the CL signal was also investigated in the range of $0.005-0.06 \mathrm{~mol} \cdot \mathrm{L}^{-1}$. According to the result of Figure 6 , the concentration of $0.01 \mathrm{~mol} \cdot \mathrm{L}^{-1} \mathrm{CoSO}_{4}$ was chosen

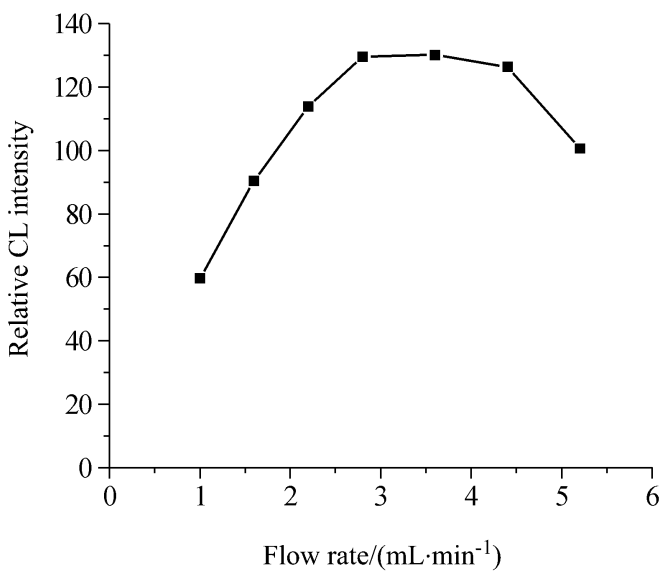

Figure 3 The effect of flow rate of carrier stream on the CL

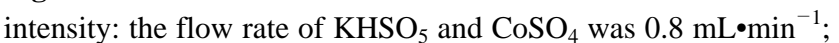
the concentrations of $\mathrm{KHSO}_{5}, \mathrm{CoSO}_{4}$ and rifampicin were 0.02 $\mathrm{mol} \cdot \mathrm{L}^{-1}, 0.01 \mathrm{~mol} \cdot \mathrm{L}^{-1}$ and $6.0 \times 10^{-7} \mathrm{~g} \cdot \mathrm{mL}^{-1}$, respectively.

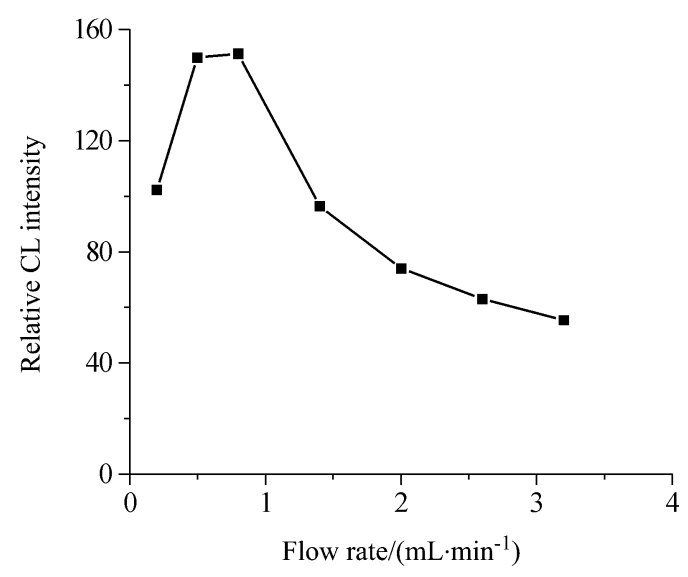

Figure 4 The effect of flow rate of $\mathrm{KHSO}_{5}$ and $\mathrm{CoSO}_{4}$ on the

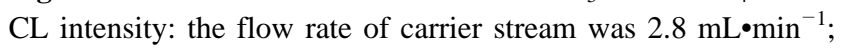
the concentrations of $\mathrm{KHSO}_{5}, \mathrm{CoSO}_{4}$ and rifampicin were 0.02 $\mathrm{mol} \cdot \mathrm{L}^{-1}, 0.01 \mathrm{~mol} \cdot \mathrm{L}^{-1}$ and $6.0 \times 10^{-7} \mathrm{~g} \cdot \mathrm{mL}^{-1}$, respectively.

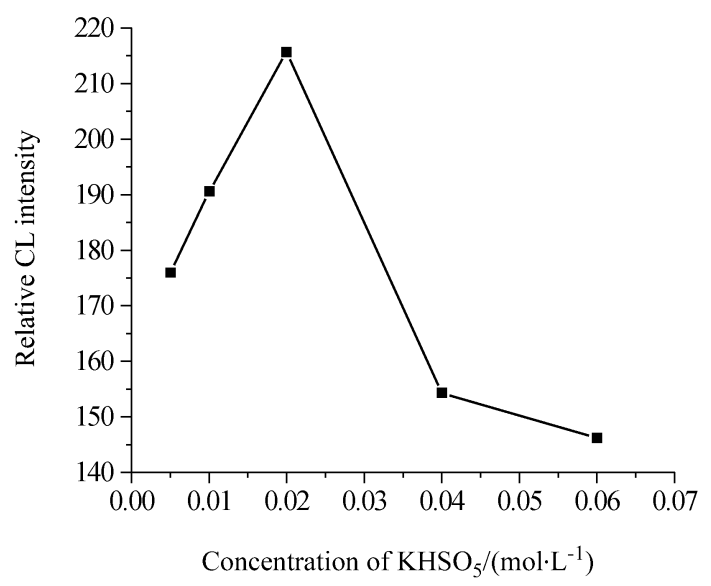

Figure 5 The effect of $\mathrm{KHSO}_{5}$ concentration on the CL intensity: the flow rate of $\mathrm{KHSO}_{5}, \mathrm{CoSO}_{4}$ and carrier stream were 0.8 , 0.8 and $2.8 \mathrm{~mL} \cdot \mathrm{min}^{-1}$; the concentrations of $\mathrm{CoSO}_{4}$ and rifampicin were $0.01 \mathrm{~mol} \bullet \mathrm{L}^{-1}$ and $6.0 \times 10^{-7} \mathrm{~g} \bullet \mathrm{mL}^{-1}$, respectively. 


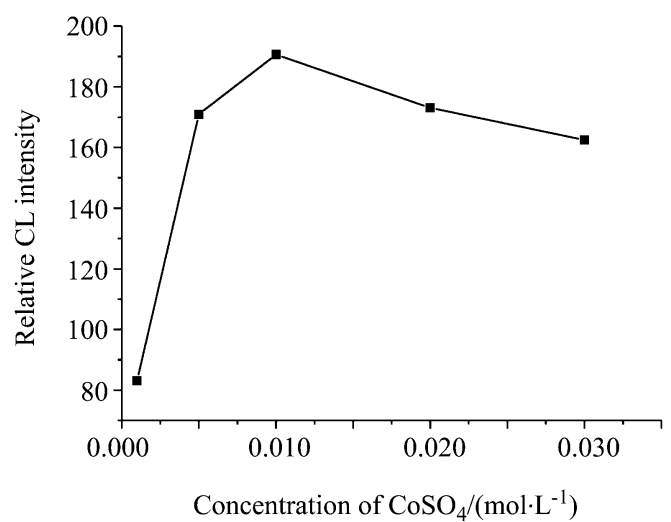

Figure 6 The effect of $\mathrm{CoSO}_{4}$ concentration on the CL intensity: the flow rate of $\mathrm{KHSO}_{5}, \mathrm{CoSO}_{4}$ and carrier stream were $0.8,0.8$ and $2.8 \mathrm{~mL} \cdot \mathrm{min}^{-1}$; the concentrations of $\mathrm{KHSO}_{5}$ and rifampicin were $0.02 \mathrm{~mol} \cdot \mathrm{L}^{-1}$ and $6.0 \times 10^{-7} \mathrm{~g} \bullet \mathrm{mL}^{-1}$, respectively.

for further experiments.

\section{Analytical performance}

Under the optimum experimental condition above, the calibration curve of relative CL intensity versus concentration over range $5 \times 10^{-8}$ to $10^{-6} \mathrm{~g} \cdot \mathrm{mL}^{-1}$ was obtained. Figure 7 shows typical recorder response to the determination of standard rifampicin solution. The $\mathrm{CL}$ intensity after subtracting the blank from the maximum peak height increased linearly with increasing the rifampicin concentration, as expressed by the equation $\Delta I=33.95 C_{\mathrm{rfp}} /\left(10^{-7} \mathrm{~g} \bullet \mathrm{mL}^{-1}\right)-17.10(r=0.9991)$. The determination limit was $7 \times 10^{-9} \mathrm{~g} \bullet \mathrm{mL}^{-1}(S / N=3)$ of rifampicin in the flow-injection-CL of $\mathrm{HSO}_{5}^{-} / \mathrm{Co}^{2+}$ system. The relative standard deviation was found to be $2.7 \%$ by 11 replicate determinations of $6 \times 10^{-7} \mathrm{~g} \cdot \mathrm{mL}^{-1}$ rifampicin.

\section{Interference}

The effect of various interferences, such as excipients and ions, on the determination of $6 \times 10^{-7} \mathrm{~g} \cdot \mathrm{mL}^{-1}$ rifampicin was investigated. A substance was considered no interference if the variation of the CL intensity was within $\pm 5 \%$. The results are listed in Table 1 . Common excipients such as starch and sugar in eye drops or capsules do not interfere the determination of rifampicin. Therefore, the proposed flow-injection-CL analysis method has adequate selectivity to the determination of rifampicin.

Table 1 Tolerable concentration ratios with respect to rifampicin $\left(6 \times 10^{-7} \mathrm{~g} \bullet \mathrm{mL}^{-1}\right)$ for some interfering species

\begin{tabular}{rl}
\hline Tolerance concentration ratio & \multicolumn{1}{c}{ Species } \\
\hline 1000 & $\mathrm{~K}^{+}, \mathrm{NH}_{4}^{+}, \mathrm{Ca}^{2+}, \mathrm{Mg}^{2+}, \mathrm{NO}_{3}^{-}$, \\
500 & $\mathrm{SO}_{4}^{2-}$ \\
100 & $D$-fructose, sucrose \\
50 & starch, glucose \\
10 & $\mathrm{Fe}^{2+}$, dextrin, \\
5 & $\mathrm{Fe}^{3+}$, citric acid \\
& ascorbic acid \\
\hline
\end{tabular}

\section{Application}

In order to evaluate the applicability and reliability of the proposed methodology, it was applied to the determination of rifampicin in real eye drop and capsule samples with the procedure that has been described in the section of sample preparation. The recoveries were checked by comparing the CL signals from the samples with those from standard rifampicin at the same concentration. The results are shown in Table 2. Furthermore, the results of eye drops were compared with

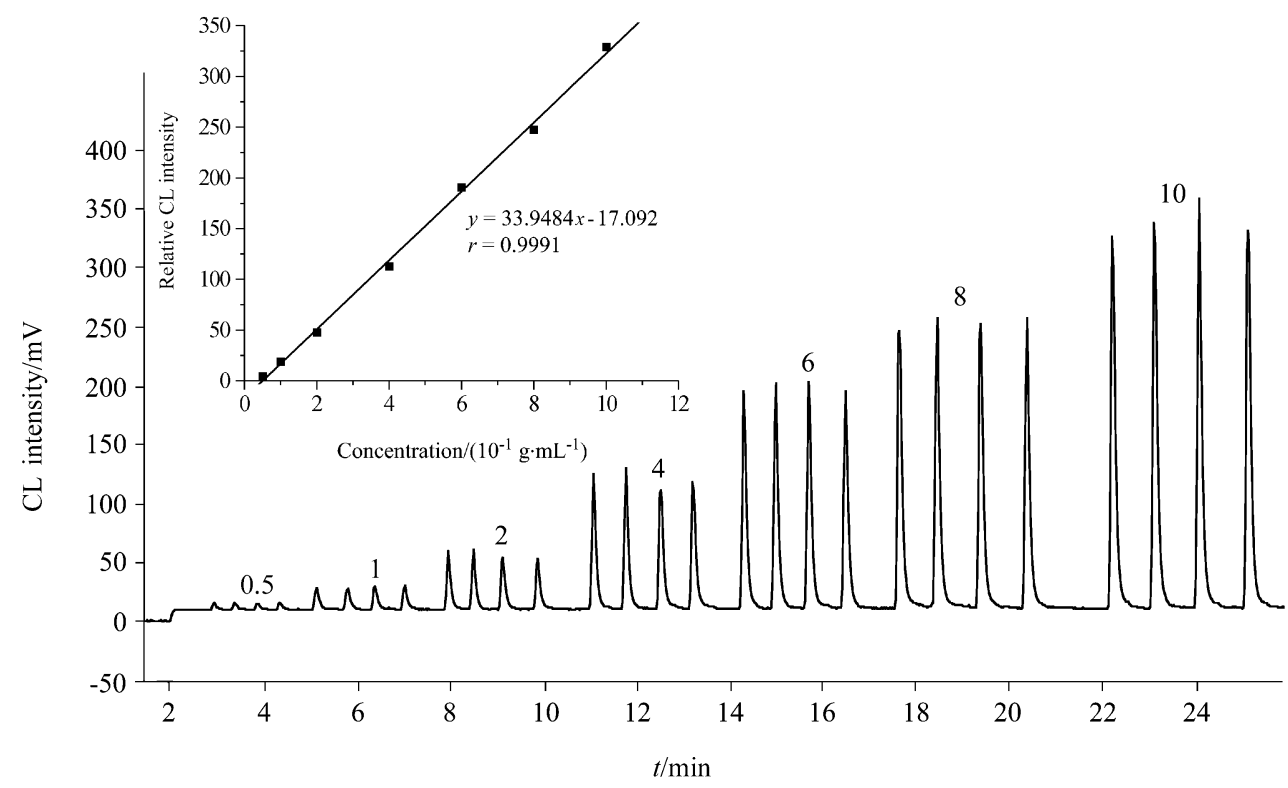

Figure 7 Typical recorder response to the determination of standard rifampicin solutions $\left(10^{-7} \mathrm{~g} \bullet \mathrm{mL}^{-1}\right)$, with the inset (the linearity relation between the CL intensity and rifampicin concentration). 
those obtained by the method described in the Pharmacopoeia. ${ }^{25}$ According to the labeled value $10 \mathrm{mg} / 10 \mathrm{~mL}$ in the eye drops, the result with the proposed method was $9.7 \mathrm{mg} / 10 \mathrm{~mL}$; and with the Pharmacopoeia method it was $10.1 \mathrm{mg} / 10 \mathrm{~mL}$, which agreed well with that obtained by spectrophotometry $\left(\lambda_{\max }=474 \mathrm{~nm}\right)$. Therefore, the recoveries were quite satisfactory and this method was reliable.

\section{Possible CL mechanism}

Many investigations have discussed the decomposition mechanism of $\mathrm{HSO}_{5}^{-}$and confirmed that the decomposition of $\mathrm{HSO}_{5}^{-}$generated singlet oxygen $\left({ }^{1} \mathrm{O}_{2}\right)$, an excited state of molecular oxygen, ${ }^{21,26,27}$ and the details are summarized as follows:

$$
\begin{aligned}
& \mathrm{HSO}_{5}^{-}+\mathrm{Co}^{2+} \rightarrow \mathrm{SO}_{4}^{\square-}+\mathrm{Co}^{3+}+\mathrm{OH}^{-} \\
& \mathrm{HSO}_{5}^{-}+\mathrm{Co}^{2+} \rightarrow \mathrm{SO}_{4}^{2-}+\mathrm{Co}^{3+}+\mathrm{OH}^{\bullet} \\
& \mathrm{Co}^{3+}+\mathrm{HSO}_{5}^{-} \rightarrow \mathrm{Co}^{2+}+\mathrm{HSO}_{5} \\
& \mathrm{HSO}_{5}^{-}+\mathrm{SO}_{4}^{\square-} \rightarrow \mathrm{SO}_{5}^{\square-}+\mathrm{HSO}_{4}^{-} \\
& \mathrm{HSO}_{5}^{-}+\mathrm{OH}^{\bullet} \rightarrow \mathrm{SO}_{5}^{\square-}+\mathrm{H}_{2} \mathrm{O} \\
& 2 \mathrm{SO}_{5}^{\square-}+\mathrm{H}_{2} \mathrm{O} \rightarrow 2 \mathrm{HSO}_{4}^{-}+3 / 2{ }^{1} \mathrm{O}_{2}
\end{aligned}
$$

Based on the former research, $\mathrm{HSO}_{5}^{-}$decomposed by the catalysis of $\mathrm{Co}^{2+}$ can produce reactive species $\left({ }^{\circ} \mathrm{OH}\right.$, $\mathrm{SO}_{4}^{\square-}, \mathrm{SO}_{5}^{\square-},{ }^{1} \mathrm{O}_{2}$, etc.), which are strong oxidants. Because rifampicin is a hydroquinone derivative that contains three phenolic hydroxyl groups and two alcoholic hydroxyl groups, it can be readily oxidated. ${ }^{20}$ The reasonable explanation about the rifampicin enhancement of $\mathrm{HSO}_{5}^{-} / \mathrm{Co}^{2+}$ may be that the hydroxyl groups on the rifampicin were oxidated by the main reactive species produced by $\mathrm{HSO}_{5}^{-} / \mathrm{Co}^{2+}$, and then formed the excited oxy-rifampicin, at last, the CL signal was emitted when the excited oxy-rifampicin decayed to the ground state. ${ }^{20}$ The possible process was proposed as:

Reactive species + rifampicin $\rightarrow$ [oxy-rifampicin]*

[oxy-rifampicin] $]^{*} \rightarrow$ oxy-rifampicin $+h v$

\section{Conclusion}

In this work, we found a strong CL phenomenon when a trace amount of rifampicin was added to peroxomonosulfate-cobalt(II) mixed solution and the CL intensity was strongly dependent on rifampicin concentration. The possible process was that the rifampicin was oxidated by reactive species $\left({ }^{\circ} \mathrm{OH}, \mathrm{SO}_{4}^{\square-}, \mathrm{SO}_{5}^{\square-}\right.$ etc.) produced by $\mathrm{HSO}_{5}^{-} / \mathrm{Co}^{2+}$. On the basis of these, a flow-injection-CL method was proposed to determine rifampicin. This method is simple, rapid and inexpen-

\begin{tabular}{|c|c|c|c|c|c|}
\hline Sample & Measured $/\left(\mathrm{g} \bullet \mathrm{mL}^{-1}\right)$ & R.S.D./\% $(n=7)$ & Added $/\left(\mathrm{g} \bullet \mathrm{mL}^{-1}\right)$ & Founded $/\left(\mathrm{g} \bullet \mathrm{mL}^{-1}\right)$ & Recovery $/ \%(n=5)$ \\
\hline \multirow[b]{2}{*}{ Eye drops } & $1.27 \times 10^{-7}$ & 1.3 & $1.5 \times 10^{-7}$ & $2.81 \times 10^{-7}$ & 102.7 \\
\hline & $2.27 \times 10^{-7}$ & 2.6 & $2.0 \times 10^{-7}$ & $4.28 \times 10^{-7}$ & 100.5 \\
\hline \multirow{2}{*}{ Capsules } & $0.72 \times 10^{-7}$ & 2.2 & $1.5 \times 10^{-7}$ & $2.24 \times 10^{-7}$ & 101.3 \\
\hline & $1.01 \times 10^{-7}$ & 0.9 & $2.0 \times 10^{-7}$ & $3.04 \times 10^{-7}$ & 101.5 \\
\hline
\end{tabular}
sive, and also has much better linearity and lower detection limit. Furthermore, the method has been used for the determination of rifampicin in real eye drop and capsule samples with satisfactory results.

Table 2 Determination of rifampicin in real eye drop and capsule samples

\section{References}

1 Panchagnula, R.; Agrawal, S. Int. J. Pharm. 2004, 1, 271.

2 Dumana, N.; Çevikbas, A.; Johansson, C. Int. J. Antimicrob. Agents 2004, 23, 84.

3 Mariappan, T. T.; Singh, S. Mol. Pharm. 2004, 1, 363.

4 Lomillo, M. A. A.; Renedo, O. D.; Martınez, M. J. A. Electrochim. Acta 2005, 50, 1807.

5 Lomillo, M. A. A.; Kauffmann, J. M.; Martınez, M. J. A. Biosens. Bioelectron. 2003, 18, 1165.

6 Acedo-Valenzuela, M. I.; Espinosa-Mansilla, A.; Peña, M.; Cañada-Cañada, F. Anal. Bioanal. Chem. 2002, 374, 432.

7 Lomillo, M. A. A.; Renedo, O. D.; Martınez, M. J. A. Electroanalysis 2002, 14, 634.

8 Lomillo, M. A. A.; Renedo, O. D.; Martınez, M. J. A. Helv.
Chim. Acta 2002, 85, 2430.

9 Salem, A. A.; Mossab, H. A.; Barsoumb, B. N. Spectrochim. Acta, Part A 2005, 62, 466.

10 Guo, W. L.; Meng, Q. F.; Lu, J. H.; Jiang, C. J.; Liang, Y. C.; Teng, L. R. Lecture Notes In Computer Science (LNCS) 2006, 3980, 938.

11 Favila, A.; Gallo, M.; Glossman-Mitnik, D. J. Mol. Model. 2007, 13, 505.

12 Aparicio, R.; Bello, M. A.; Callejón, M.; Guiraúm, A. Biomed. Chromatogr. 2006, 20, 748.

13 Calleja, I.; Blanco-Pr'́eto, M. J.; Ruz, N.; Renedo, M. J.; Dios-Viéitez, M. C. J. Chromatogr., A 2004, 1031, 289.

14 Mohan, B.; Sharda, N.; Singh, S. J. Pharm. Biomed. Anal. 2003, 31, 607 .

15 Cheng, X. L.; Zhao, L. X.; Lin, J. M. Chin. J. Chem. 2006, 
24,65 .

16 Wei, S. L.; Zhao, L. X.; Cheng, X. L.; Lin, J. M. Chin. J. Chem. 2007, 25, 535.

17 Chen, F. N.; Zhang, Y. X.; Zhang, Z. J. Chin. J. Chem. 2007, 25, 942 .

18 Li, B. X.; He, Y. Z.; Lü, J. G.; Zhang, Z. J. Anal. Bioanal. Chem. 2005, 383, 817.

19 Yang, W. P.; Zhang, Y. T.; Zhang, Z. J. Acta Chim. Sinica 2003, 61, 303 (in Chinese).

20 Liang, Y. D.; Song, J. F.; Xu, M. Spectrochim. Acta, Part A 2007, 67, 430 .

21 Wang, M.; Zhao, L. X.; Liu, M. L.; Lin, J. M. Spectrochim.
Acta, Part A 2007, 66, 1222.

$22 \mathrm{Su}, \mathrm{R} . \mathrm{G} . ; \mathrm{Wu}$, J. J.; Qu, F.; Lin, J. M. Environ. Chem. 2003, 22, 278.

23 Tsukada, S.; Miki, H.; Lin, J. M.; Suzuki, T.; Yamada, M. Anal. Chim. Acta, 371, 163.

24 Lin, J. M.; Yamada, M. Anal. Chem. 2000, 72, 1148.

25 Editorial Committee of China Pharmacopoeia, China Pharmacopoeia Part II, People's Health Press, Beijing, 1995, p. 301 (in Chinese).

26 Mariano, M. H. Anal. Chem. 1968, 40, 1662.

27 Wang, M.; Zhao, L. X.; Lin, J. M. Luminescence 2007, 22, 182.

(E0707302 ZHAO, X. J.; FAN, Y. Y.) 